\title{
The Accounting Analysis of the Intangible Cultural Heritage Enterprises' Brand Value-Take the Chinese Medicine Industry as an Example
}

\author{
Biyun Lin \\ School of Business, University of Hohai, Nanjing, China \\ Email: 15850671899@163.com
}

How to cite this paper: Lin, B.Y. (2018) The Accounting Analysis of the Intangible Cultural Heritage Enterprises' Brand Value-Take the Chinese Medicine Industry as an Example. American Journal of Industrial and Business Management, 8, 1716-1731. https://doi.org/10.4236/ajibm.2018.87115

Received: June 22, 2018

Accepted: July 21, 2018

Published: July 24, 2018

Copyright $\odot 2018$ by author and Scientific Research Publishing Inc. This work is licensed under the Creative Commons Attribution International License (CC BY 4.0).

http://creativecommons.org/licenses/by/4.0/ (c) (i) Open Access

\begin{abstract}
Intangible cultural heritage enterprises have geographical, cultural and technical characteristics. Different from other general enterprises, its brand has a profound traditional cultural intrinsic. Therefore, when companies undertake greater responsibility to protect and inherit it, they should also consider how to use and develop resources to increase their brand value. The article quantitatively calculated and analyzed the brand value of an enterprise based on an accounting perspective. Taking the Chinese medicine industry as an example, the article selected the financial data of three brands, namely Tong Ren Tang, Dong E-Ejiao, and Yunnan Baiyao, as the calculation basis. We use the improved "Interbrand assessment model" to identify existing weaknesses in the relatively weak brand companies and find common and individual problems, such as low levels of management, difficulty in cost control, small profit margins, and easily damaged brand images. Finally, we will provide countermeasures to enhance the brand value of intangible cultural heritage companies from increasing effective investment, effectively controlling costs, increasing profits through innovation, and strengthening cooperation with various organizations of society.
\end{abstract}

\section{Keywords}

Intangible Cultural Heritage, Brand Value, Accounting Analysis, Chinese Medicine Industry

\section{The Necessity and Significance of Research}

\subsection{Necessity}

\subsubsection{National Attention to the Management of Intangible Cultural Heritage}

Since the "18th National Congress" of the Chinese Communist Party, state lead- 
ers have attached great importance to the management of intangible cultural heritage. General Secretary Xi Jinping has delivered many important speeches on the protection and promotion of the traditional Chinese culture and made important instructions [1]. For example, on April 12, 2016, Xi Jinping gave an important instruction to the cultural relics work: "The cultural relics, bearing a splendid civilization, inheriting the historical culture, and maintaining the national spirit, are the valuable legacy left by our ancestors and the deep nourishment to strengthen the building of socialist spiritual civilization." At the "19th National Congress", the task of "strengthening the heritage conservation and use of cultural heritage protection" has also been emphasized many times. In order to allow the intangible cultural heritage to be better developed and protected, the state has also introduced a series of laws and regulations. "The Law of the People's Republic of China on the Intangible Cultural Heritage" promulgated in 2011; the General Office of the National Development and Reform Commission, the General Office of the Ministry of Culture in 2014 issued the "Notification on the Implementation of the National Non-material Cultural Heritage Protection and Utilization Facilities Construction Plan"; In 2017, the Ministry of Finance issued a special fund for the protection of intangible cultural heritage [2].

\subsubsection{Market Demand for the Development of Intangible Cultural Heritage Resources}

While the state pays more attention to the protection of intangible cultural heritage and the increase in social awareness, the opportunities for the development of intangible cultural heritage resources have increased in the market economy, such as the development of folk activities, folk performing arts, traditional knowledge and skills. Since the 21st century, with the rapid economic development of our country and the improvement of people's living standards, we have given them opportunities for industrialization. Many companies with intangible resources seized the opportunity to rapidly develop this cultural and economic resource. They met the market demand, established brands, and formed large companies with lead position in the market. Such as Jiangsu Heng Shun Group Co., Ltd., Beijing Tong Ren Tang (Group) Co., Ltd. and so on. These brand values are increasingly valued by consumers and investors and become an important indicator of the soft power of these companies. Therefore, analyzing the value of its brand based on accounting perspective can not only analyze its impact on the company's financial indicators, but also reflect the value of its market.

\subsection{The Significance of Sustainable Development of the Company}

\subsubsection{Strengthen Managers' Understanding of Branod Value}

The marketization of brand value can allow the managers of intangible cultural heritage enterprises to take a more rational view of the value of their own national brand, and do not blindly overestimate or ignore the value of this resource. Analyze the brand's value based on factors such as cost and profit, and 
compare it with the brand value of competitors in the same industry. Such as “Tong Ren Tang" and "Dong E-Ejiao" company, both are the country's wellknown Chinese medicine non-material cultural heritage enterprises. In recent years, from news reporting, Dong E-Ejiao brand value far exceeds Tong Ren Tang. In this regard, business operators can use data to find out the reasons for the gap, then formulate a reasonable brand marketing strategy and business management decisions based on this information, which can further enhance the brand value of companies.

\subsubsection{Enrich the Contents of Corporate Balance Sheets}

A higher brand value can lower the asset-liability ratio, show a better financial status, enhance investor confidence, and facilitate the further financing of the company. For example, Jiangsu Heng Shun Group Co., Ltd. has special "solid state layered fermentation" and other technologies. In 2006, this brewing technique was included in the first "National Intangible Cultural Heritage Protection List". This technique has embodied Zhenjiang's vinegar essence for more than a thousand years, represented the traditional features and the highest level of vinegar technology in southern China, which has a high historical, cultural and social value. In 2017, the company's net asset ranking was 34 , which was in the middle of the industry. If the brand value is included in the statement as an asset, the company's strength and performance will be more reasonably displayed, allowing the outside world to see the investment value of the intangible cultural heritage company, which will help them reduce the difficulty of raising funds.

\subsubsection{Improve Their Market Value}

From intangible process technology to consumer products that can produce social benefits, this is the gradual realization of the intangible cultural heritage resources through the formation of the brand's marketization after protection and development. The level of a brand's market position is often expressed through a number of quantitative indicators, which are based on corporate financial data. For example, data released by Moutai official website, there were multiple assessment agencies deem that in 2017, Kweichow Moutai Co., Ltd. belonged to a "Global Brand Value 500", ranking first in the world's listed companies with more than $\$ 7$ billion worth of brand value, a total market value of more than RMB 50 billion. Due to the high brand value, investors, creditors, and consumers have absolute trust in their brands. Therefore, as the stock price rises, its market value continues to increase.

\section{Research Method: "Interbrand Assessment Model"}

\section{1. "Interbrand Assessment Model"}

"Interbrand Assessment Model" was put forward by British Interbrand Company which was established in 1974. It is the first brand value evaluation method that has passed ISO authority certification. In China, this method has been recognized by the academic community. For example, Professor Xiao Xiang (2007) 
of Beijing Jiaotong University evaluated and applied the model in "Analysis of Brand Value Assessment Method and Its Value Influencing Factors" [3]; professor Xiang Yinshi (2009) analyzed the market performance of brand competitiveness based on this model [4]; professor Tian Jie (2015) used the "Interbrand Assessment model" to research the brand improvement of high-tech innovative companies [5].

"Interbrand Assessment Model" takes market performance as the main evaluation basis, uses the present value of currency as the value evaluation result, and comprehensively evaluates brand value based on financial and market perspectives. Although it is more objective and reasonable than the traditional assessment method, there are also limitations: There are large uncertainties in the prediction of sales and profit for several years in the future; the brand effect index adopts the "specialist scoring method", which has a great subjectivity [6]. Therefore, in order to obtain more accurate brand value, this article will use an improved assessment model for analysis.

\subsection{Construction and Improvement of "Interbrand Assessment Model"}

\subsubsection{Original "Interbrand Assessment Model"}

Calculation formula:

$$
\begin{aligned}
& V=B \times S \\
& B=q \times G
\end{aligned}
$$

In formula (1), $V$ is the brand value, $B$ is the brand's excess net profit, and $S$ is the brand strength multiple. In formula (2), $G$ is the company's annual net profit, and $q$ is the brand effect index.

\subsubsection{Improved "Interbrand Assessment Model"}

\section{1) Improvement of $B$}

In order to reduce the impact of $q$ with more subjective factors, more analysis based on the company's financial perspective will use the main income as the basis data to reflect the management situation of the company. The value assessment still uses $V=B \times S$ to introduce the capital output ratio and the capital profit rate. The specific steps are as follows:

Let $M$ be the main income of enterprises. In order to reduce the impact of business fluctuations, $\mathrm{M}$ is the weighted average of the past three years. The formula is as follows:

$$
M=\left(M_{1}+2 M_{2}+3 M_{3}\right) / 6
$$

Let $T$ be the investment capital, and the capital output ratio $J=M / T$, then there are:

$$
T=M / J
$$

Estimate the normal return, count the normal return of input $T$ as $E_{0}$, and set $R$ as the normal return of capital input without considering the use of brand: 


$$
E_{0}=R \times T=R \times M / J
$$

Determine the brand excess profit $B$, set $F$ as the company's main profit margin, $E$ is the company's main profit:

$$
E=M \times F
$$

Among them,

$$
F=\left(F_{1}+2 F_{2}+3 F_{3}\right) / 6
$$

The brand's excess net profit $B=E-E_{0}=M(F-R / J)(1-t), t$ is corporate income tax.

In this way, the brand value is calculated and the company's financial information is fully utilized. Based on the main income, the capital output rate $J$ and the capital profit rate $R$ ( $J, R$ can be calculated by the National Bureau of Statistics or financial reports).

\section{2) Improvement of $S$}

The original "Interbrand assessment model" calculates the brand strength scores by weighting the weights from the seven aspects of market position, stability, marketing scope, brand support, internationality, brand trends, and brand protection. The newly established model will adjust the influencing factors according to the characteristics of different industries, and use the data as the support to calculate the corresponding indicators for each factor. Then, each index value is processed dimensionlessly. Finally, the weight of each factor is calculated. Refer experts to score and calculate the final brand score. Specific steps are as follows:

Determination of Factors and Index Values

\begin{tabular}{cc}
\hline Factors & Index Values \\
\hline $\mathrm{C} 1$ & $\mathrm{D} 1$ \\
$\mathrm{C} 2$ & $\mathrm{D} 2$ \\
$\mathrm{C} 3$ & $\mathrm{D} 3$ \\
$\mathrm{C} 4$ & $\mathrm{D} 4$ \\
$\mathrm{C} 5$ & $\mathrm{D} 5$ \\
$\mathrm{C} 6$ & $\mathrm{D} 6$ \\
$\mathrm{C} 7$ & $\mathrm{D} 7$ \\
\hline
\end{tabular}

\section{Determination of Index Weights}

Because each index has different magnitudes and dimensions, and cannot be compared, the coefficient of variation is used to eliminate the above-mentioned effects, and measure the degree of difference between the indexes. The formula is as follows:

$$
V_{i}=\frac{\sigma_{i}}{\bar{x}_{i}}, i=1,2,3,4,5,6,7
$$

Among them, $V_{i}$ is the coefficient of variation of the i-th index, $\sigma_{i}$ is the standard deviation of the $\mathrm{i}$-th index, and $\bar{x}_{i}$ is the arithmetic mean of the $\mathrm{i}$-th index. 
Calculate the coefficient of variation, and then you can calculate the weight of each indicator, that is:

$$
\omega_{i}=\frac{\sigma_{i}}{\sum_{i=1} \sigma_{i}}, i=1,2,3,4,5,6,7
$$

Calculation of Brand Value

The weighted score $n$ is calculated by $\omega_{i}$ and expert score, which are brought into the following formula to obtain the value $S$ of the brand value.

$$
\begin{cases}S^{2}=2 n, & n \in[0,50] \\ (S-10)^{2}=2 n-100, & n \in[50,100]\end{cases}
$$

\subsubsection{Application and Analysis of the New Model \\ 1) Case Introduction}

Taking the Chinese medicine industry as an example, three representative companies are selected: Beijing Tongrentang Co., Ltd., Dong'e Ejiao Co., Ltd., and Yunnan Baiyao Group Co., Ltd. Among these three brands, Tong Ren Tang's TCM culture has been included in the first national intangible cultural heritage list, numbered 446 IX-7. The Dong'e donkey-hide gelatin production technique is part of the traditional Chinese intangible cultural heritage, which is also the first national intangible cultural heritage and numbered 443IX-4. Although Yunnan Baiyao has not been included in the list of intangible cultural heritage, its formula has always been listed as a state secret and has been produced for more than a century. It is also an old brand with unique features of traditional medicine.

\section{2) Reason for the Selection}

These three pharmaceutical brands have a long history and strong traditional cultural heritage. From the perspective of development in recent years, Dong'e Ejiao and Yunnan Baiyao rank among the top few in the pharmaceutical industry, surpassing Tong Ren Tang, which is also a time-honored brand. The reasons for the gap are worth exploring. Moreover, these three companies are listed companies. Their disclosure of financial information is open and accurate, which facilitates the calculation of the final brand value. Therefore, this paper selects the operating results of these three brand enterprises in the past three years for evaluation.

\section{3) Specific Application}

As shown in Table 1, the 2012-2016 financial data of the three brand enterprises are derived from the 2012-2016 annual report of Beijing Tongrentang Co., Ltd., Dong'e Ejiao Co., Ltd. and Yunnan Baiyao Group Co., Ltd.:

The data for 2012-2013 was mainly used to calculate main income $M$ and main profit rate $F$ in the past three years, and can be calculated according to formula (3) and formula (6). Among them, $J=1.25$, which was combined with relevant data from the National Bureau of Statistics. The replacement of capital stock with total capital was for convenience of calculation (Table 2). Among them, capital output ratio $=$ total output value/capital stock, including capital 
Table 1. Financial data of three enterprises. (Unit: 100 million yuan)

\begin{tabular}{ccccccc}
\hline & \multicolumn{2}{c}{ Tongrentang } & \multicolumn{2}{c}{ Dong'e Ejiao } & \multicolumn{2}{c}{ Yunnan Baiyao } \\
\cline { 2 - 7 } & $\begin{array}{c}\text { Main } \\
\text { business } \\
\text { income }\end{array}$ & $\begin{array}{c}\text { Main } \\
\text { profit rate }\end{array}$ & $\begin{array}{c}\text { Main } \\
\text { business } \\
\text { income }\end{array}$ & $\begin{array}{c}\text { Main profit } \\
\text { rate }\end{array}$ & $\begin{array}{c}\text { Main } \\
\text { business } \\
\text { income }\end{array}$ & $\begin{array}{c}\text { Main } \\
\text { profit rate }\end{array}$ \\
\hline 2012 & 75.04 & $13.98 \%$ & 30.56 & $40.35 \%$ & 136.87 & $13.18 \%$ \\
2013 & 87.15 & $14.50 \%$ & 40.16 & $35.31 \%$ & 158.15 & $16.69 \%$ \\
2014 & 96.86 & $15.49 \%$ & 40.09 & $39.71 \%$ & 188.14 & $15.04 \%$ \\
2015 & 108.09 & $16.31 \%$ & 54.50 & $35.23 \%$ & 207.38 & $15.28 \%$ \\
2016 & 120.91 & $15.61 \%$ & 63.17 & $34.24 \%$ & 224.11 & $14.81 \%$ \\
\hline
\end{tabular}

Table 2. Estimation of capital output rate. (Unit: 100 million yuan)

\begin{tabular}{cccc}
\hline & 2014 & 2015 & 2016 \\
\hline Industry Output Value & 25,798 & 26,703 & 32,395 \\
Total Capital & $21,739.42$ & $25,071.09$ & $28,789.11$ \\
Capital Output Ratio & 1.19 & 1.07 & 1.13 \\
\hline
\end{tabular}

stock < capital comprehensive. Combining historical data with characteristics of the pharmaceutical industry, the capital output ratio for the past three years was estimated to be $J=1.25$.

With the above calculated $J$ and $M$, the input cost $T$ can be calculated (Table 3).

Finally, through the formula, we can complete the calculation of the first brand's excess net profit (Table 4). The income tax rate for the pharmaceutical industry was 15\% (Note: The sources of data in this article were mainly the Shanghai Stock Exchange, the annual report of the enterprise, the Oriental Wealth Network, the National Bureau of Statistics, the China Industrial Information Network, and the China Chamber of Commerce Industry).

Based on the characteristics of the pharmaceutical industry and the commonality of intangible cultural heritage companies, the following seven factors and seven corresponding indicators would be used to calculate brand strength (Table 5).

The specific index values (Table 6), and the values of each indicator for three years were obtained. After dimensionless processing, the coefficient of variation of each indicator was obtained, and the weight of each indicator was finally calculated according to formula (8) (Table 7).

Refer to the expert's score in the reference material to calculate the weighted average score. According to the score range, see formula (9) and bring the value into the formula corresponding to the interval to get the final S (Table 8).

Finally, use the formula: brand value $=$ brand excess net profit $\times$ brand strength to calculate the final brand value of the three companies from 2014 to 2016 (Table 9).

In order to verify the accuracy of the final results, this report has sought the 
Table 3. Input cost of three companies 2014-2016. (Unit: 100 million yuan)

\begin{tabular}{cccc}
\hline & Tongrentang & Dong’e Ejiao & Yunnan Baiyao \\
\hline 2014 & 71.99 & 30.82 & 135.68 \\
2015 & 80.69 & 37.85 & 154.21 \\
2016 & 90.10 & 45.15 & 170.03 \\
\hline
\end{tabular}

Table 4. Brand excess net profit of three enterprises in 2014-2016. (Unit: 100 million yuan)

\begin{tabular}{cccc}
\hline & Tongrentang & Dong'e Ejiao & Yunnan Baiyao \\
\hline 2014 & 5.53 & 10.04 & 10.96 \\
2015 & 6.91 & 11.68 & 12.71 \\
2016 & 7.79 & 13.34 & 13.24 \\
\hline
\end{tabular}

Table 5. Contents of seven indicators.

\begin{tabular}{|c|c|c|}
\hline Factors & System Indicators & Indicator Description \\
\hline Market Status & Market Share & $\begin{array}{c}\text { The First Five Years of Average } \\
\text { Sales/Industry Sales }\end{array}$ \\
\hline Stability & Revenue Strength & $\begin{array}{l}\text { Net Asset Profit Rate/Average Net } \\
\text { Interest Rate of the Industry }\end{array}$ \\
\hline $\begin{array}{l}\text { Expansion } \\
\text { Capacity }\end{array}$ & Growth Rate & $\begin{array}{c}\text { The Natural logarithm of the } \\
\text { Company's Total Assets }\end{array}$ \\
\hline Welfare & Brand Welfare Level & $\begin{array}{c}\text { The Sum of Financial Statements } \\
\text { Surplus Reserve/Ownership }\end{array}$ \\
\hline Internationalism & Export exchange rate & Export Income/Sales Revenue \\
\hline Brand Support & $\begin{array}{l}\text { Technology R\&D } \\
\text { Investment Rate }\end{array}$ & Technology R\&D Investment/Sales Revenue \\
\hline Competitiveness & $\begin{array}{l}\text { Brand Competition } \\
\text { Investment }\end{array}$ & Sales Expenses/Total Operating Costs \\
\hline
\end{tabular}

Table 6. Indicator values of 2014-2016 for three enterprises.

\begin{tabular}{cccccccccc}
\hline & \multicolumn{2}{c}{ Tongrentang } & \multicolumn{2}{c}{ Dong' Ejiao } & \multicolumn{2}{c}{ Yunnan Baiyao } \\
\hline Year & 2014 & 2015 & 2016 & 2014 & 2015 & 2016 & 2014 & 2015 & 2016 \\
Market Share & $0.40 \%$ & $0.36 \%$ & $0.35 \%$ & $0.19 \%$ & $0.17 \%$ & $0.16 \%$ & $0.75 \%$ & $0.68 \%$ & $0.65 \%$ \\
Revenue Strength & 0.64 & 0.65 & 0.57 & 1.30 & 1.23 & 1.14 & 1.08 & 0.93 & 0.76 \\
Growth Rate & 4.86 & 4.97 & 5.14 & 4.31 & 4.46 & 4.60 & 5.10 & 5.26 & 5.50 \\
Brand Welfare Level & $5.44 \%$ & $4.84 \%$ & $4.83 \%$ & $7.73 \%$ & $6.58 \%$ & $5.56 \%$ & $5.98 \%$ & $3.47 \%$ & $5.36 \%$ \\
Export exchange rate & $5.43 \%$ & $6.07 \%$ & $6.15 \%$ & $2.99 \%$ & $4.62 \%$ & $4.21 \%$ & $0.14 \%$ & $0.00 \%$ & $0.69 \%$ \\
$\begin{array}{c}\text { Technology R\&D } \\
\text { Investment Rate }\end{array}$ & $0.62 \%$ & $1.73 \%$ & $1.67 \%$ & $3.13 \%$ & $2.86 \%$ & $2.66 \%$ & $0.84 \%$ & $0.48 \%$ & $0.40 \%$ \\
$\begin{array}{c}\text { Brand Competition } \\
\text { Investment }\end{array}$ & $21.36 \%$ & $23.60 \%$ & $23.74 \%$ & $29.81 \%$ & $34.69 \%$ & $37.97 \%$ & $15.10 \%$ & $15.27 \%$ & $14.73 \%$
\end{tabular}


Table 7. Weights of brand intensity indicators.

\begin{tabular}{cc}
\hline Indicator System $\rightarrow$ Brand Factor & Weights \\
\hline Market Share & 0.19 \\
Revenue Strength & 0.10 \\
Growth Rate & 0.03 \\
Brand Welfare Level & 0.07 \\
Export exchange rate & 0.25 \\
Technology R\&D Investment Rate & 0.23 \\
Brand Competition Investment & 0.13 \\
\hline
\end{tabular}

Table 8. Brand score.

\begin{tabular}{ccc}
\hline Tongrentang & Dong'e Ejiao & Yunnan Baiyao \\
\hline 74 & 72.9 & 70.95 \\
\hline
\end{tabular}

Table 9. Results of the brand value analysis. (Unit: 100 million yuan)

\begin{tabular}{cccc}
\hline & Tongrentang & Dong'e Ejiao & Yunnan Baiyao \\
\hline 2014 & 93.58 & 168.40 & 180.53 \\
2015 & 116.89 & 195.91 & 209.29 \\
2016 & 131.94 & 223.62 & 218.03 \\
\hline
\end{tabular}

leaderboard of Chinese brands released at the "World Brand Congress" sponsored by the World Brand Lab in 2016. Dong-E E-Jiao and Yunnan Baiyao were on the list (Table 10).

Although the final value is somewhat different, it is not greater than or less than $50 \%$ of the published data, so the application of this model is reasonable.

\section{4) Commentary on Brand Value Analysis Data}

Through horizontal and vertical comparative analysis, it can be seen that in Table 9, the brand value of the three companies from 2014 to 2016 is increasing year by year. Judging from the calculated data and actual rankings, Dong'e Ejiao and Yunnan Baiyao were undifferentiated. As a traditional TCM culture, Tong Ren Tang's brand value was rising year by year, but there was a certain gap between them. Based on the above-mentioned analysis of financial data, Tong Ren Tang was mainly used to reflect problems in the construction of corporate brands, and to find out the reasons from the aspects of management level, production cost, profitability, and brand image.

a) Management Level to Be Improved

From Table 4, it can be seen that in recent years, the excess net profit of Tong Ren Tang was lower than that of the other two brands. By the formula: $\mathrm{B}=$ $\mathrm{M}(\mathrm{FR} / \mathrm{J})(1-\mathrm{t})$, both $\mathrm{R}$ and $\mathrm{J}$ were the same and only $\mathrm{M}$ and $\mathrm{F}$ are different. The larger $\mathrm{M}$ of the Tong Ren Tang was caused by the lower $\mathrm{F}$. Therefore, through the comparison of the profit statements of the three companies, Tong Ren Tang's operating costs were higher, and the management costs were much higher 
Table 10. 2016 world brand lab brand value ranking.

\begin{tabular}{cccc}
\hline Ranking & Brand Name & Brand Ownership Organization & Brand Value \\
\hline 53 & Hai Wang & Shenzhen Haiwang Group & 447.85 \\
158 & Hu You & Yangtze River Pharmaceutical Group & 223.85 \\
178 & Yunnan Baiyao & Yunnan Baiyao Group & 198.58 \\
180 & Ma Ying Long & Ma Ying Long Pharmaceutical Group & 194.56 \\
231 & Dong' Ejiao & Dong' Ejiao Co., Ltd. & 142.16 \\
238 & North China & North China Pharmaceutical Group & 140.91 \\
& Pharmaceutical & Jiangxi Jiangzhong Pharmaceutical & 140.85 \\
239 & Jiang Zhong & (Group Limited) Lability Company & \\
& Baiyun & Guangzhou Baiyunshan Pharmaceutical Co., Ltd. & 139.72 \\
245 & Mountain & Shi Yao Pharmaceutical Group & 135.41 \\
\hline
\end{tabular}

than the other two. In 2016, for example, the management costs of Tong Ren Tang in 2016 were as high as more than one billion yuan, while Dong'e Ejiao and Yunnan Baiyao were only more than 400 million yuan. There are many reasons for the excessively high enterprise management fees. For example, the cost control work is not enough. When enterprises adjust income, they sometimes use bad debt preparation subjects to adjust the income level of the company. This will seriously affect the efficiency and quality of management cost control [7]. There are also some losses caused by hidden costs [8], for example, leaders' misalignment and mistakes in brand positioning and strategic decision-making will result in rising management costs.

\section{b) Unreasonable Cost Control}

Some scholars believed that there were widespread difficulties in cost control for non-heritage enterprises. Because in the brand's growth and development, in addition to the production costs directly related to the product, there were a series of indirect advertising costs, such as technical inheritance costs, legal protection fees, research fees, brand marketing channel construction fees, brand supply chain construction fees [9]. All relevant costs need to be planned rationally and controlled flexibly. If the cost is too high or too low, it is not good. It should be based on its contribution to brands and products. Tong Ren Tang had problems with the control of raw material costs. From the strength of three years of Tong Ren Tang in Table 6, it can be seen that Tong Ren Tang was at a relatively low level. The main factor that determines the strength of revenue is profit. According to relevant data, the raw materials of the company were produced by itself, some of the outsourcing, and the proportion of raw materials in the company's manufacturing cost was approximately between $50 \%-60 \%$. The self-sufficiency rate of raw materials was very low, basically relying on market procurement. At present, the self-sufficiency ratio of raw materials was about $10 \%-20 \%$, and TRT's raw material reserves were very large. Therefore, the balance sheet showed 
that the inventory ratio was high, meaning that the fixed assets occupy a lot of living resources. The turnover rate of assets was also low and was much worse than that of Dong'e Ejiao and Yunnan Baiyao.

\section{c) Small Room for Profit Increase}

The main indicators for assessing the profitability of a company based on its financial perspective are the net sales rate, total asset net rate and equity net rate. From 2014-2016 Tongrentang's financial statements, it can be calculated that the sales net profit rate was $7.88 \%, 8.10 \%$, and $7.71 \%$. There was a decrease of 0.39 percentage points from 2015-2016, and the ultimate profitability of the company was weakening. The total asset net rate is the key to corporate profitability, which was $10.09 \%, 10.74 \%$, and $9.95 \%$ respectively. It still showed a declining trend from 2015 to 2016, and the forecasted profitability was declining. The net interest rate of equity was $8.88 \%, 8.01 \%$, and $7.70 \%$, respectively and these data were declining year by year. Trends indicate that the overall profitability of enterprises has been declining in recent years, and the space for profit growth is decreasing. Relevant research showed that the process of obtaining profits by enterprises was a closed loop, including four key elements of profit analysis, strategic planning, performance management, and lean improvement [10]. The reduction of profit space reflected by financial data was also reflected the problems such as the company's strategy of obtaining profits.

\section{d) Damage Brand Image Easily}

In addition to the benefits of production and operations, which affect the survival and development of the company, the brand image of the company is also one of the most important factors. Compared with other companies, the brand image of intangible companies is easily damaged, and the consequences of damage will be very serious. China Economic Net reported that in China (Group) Co., Ltd., its roast duck technique was included in the intangible cultural heritage, and in 2012 it broke the news that it bought duck oil and waste oil from its two stores, and resold it to fried crispy traders. After the incident, the company publicly apologized until it was strongly questioned by the media and consumers. After the incident, the company publicly apologized until it was strongly questioned by the media and consumers. Because employees and companies did not maintain their brand image for the first time, the image of the company declined and the brand value decreased. In recent years, Tong Ren Tang's market reputation has declined, as in Tong Ren Tang Zibo pharmacies selling inferior drugs, and in 2013 the British Drugs and Health Products Administration (MHRA) issued a warning on the official website, saying that traditional Chinese medicines such as Tong Ren Tang contained harmful toxins [11]. This negative news undoubtedly damaged its brand image.

\section{Measures to Promote Brand Value of Non-Material Cultural Heritage Enterprises}

In view of the case analysis of the intangible cultural heritage brand value and 
the particularity of it, the countermeasures for upgrading the brand value of the intangible company will be given from the perspective of accounting.

\subsection{Increase Effective Capital Investment}

\subsubsection{Capital Investment Should Be "Based on Local Conditions"}

The state's capital investment in intangible cultural heritage is very important and has a policy guiding role. The government must formulate fund transfer plans based on the development of different heritages. For example: For example, for the well-developed intangible companies such as Dong'e Ejiao, Maotai, etc., the state's funds are no longer supportive, but rather an investment, so they can be placed on projects where companies generate economic benefits. For some intangible cultural heritages that are just starting out and are in backward areas, funds should not be directly delivered to the inheritors. Instead, firstly, they should be used to build a number of distinctive intangible cultural heritage demonstration bases. The development of these enterprises should follow the dual laws of cultural development and market economy. Industrialize their appropriate development parts.

\subsubsection{Develop Intangible Assets Trading Market}

An active market for intangible assets is conducive to the transfer or auction of pledges of intangible assets, thus guaranteeing the realization of creditor's rights. Banks are more willing to provide loans for intangible assets pledges [12]. Many intangible companies in their infancy require a large amount of capital investment. It is not enough to rely on government support alone. It also requires the support of financial institutions. Therefore, establishing a national unified trading market for intangible assets about the Chinese medicine industry, perfecting the laws and regulations in intangible assets transactions, and evaluating the value of standardized intangible assets will reduce the financing difficulties of intangible assets and obtain more funds.

\subsection{Reasonable Control of Operating Costs}

\subsubsection{Establish an Efficient Cost Management System}

Many intangible cultural heritage enterprises blindly attach importance to output, neglecting the control of costs or directly applying the management models of other enterprises to themselves. These will result in a certain degree of waste and inefficiency. Each intangible company has its own characteristics of region, culture and consumption functions. The cost management system formulated with the characteristics of its own product life cycle, core business, and corporate culture is more targeted so as to effectively avoid waste of resources, reasonably control the production cost, reduce the valueless cost, and increase the economic benefits.

\subsubsection{Motivate Employees to Control Costs}

MengFan sheng (2011) believed that in order to enable cost control standards to effectively control costs at the right time, companies needed to dynamically 
manage cost control standards [13]. The so-called dynamic management is to make cost control more effective in the hands of employees, rather than the hands of the system. For example: First, according to the survey of the attitude and ability of employees in different positions to control costs, and then establish two levels of cost standards to staff. One is the basic requirements for employees to meet the cost of control, and the other is the best model's achievements for the cost control. Inspired by incentive policies, according to psychological research, most employees will not stand still, but will work toward the second level. Not only can this effectively control costs, but also enhance the cohesion of the company.

\subsection{Increase Profits with Innovation}

\subsubsection{Increase Core Technology Innovation}

In an increasingly competitive market, if companies want to continue to maintain their own competitive advantages and make the brand continue to emit new vitality, technological innovation is essential. Wei Shouhua (2015) believed that companies should pay more attention to R \& D efficiency, not simply emphasis on R\&D investment [14]. Therefore, non-material enterprises should use more funds for the research and development of core technologies, and pay attention to diversified development. For example, intangible cultural heritage like traditional craftsmanship can generate many derivative products through innovation, thereby expanding the market share of the company and increasing profitability. Therefore, in order to achieve better development, non-heritage enterprises must not follow the rules, step by step, but continue to innovate, so that the brand can continue to flourish.

\subsubsection{Strengthen Corporate Culture, System and Talent Innovation}

Culture, system, and talents have almost consolidated all of the company's soft power and are the key points for corporate profit mining. The brand of non-material cultural legacy companies has strong traditional Chinese cultural characteristics. Companies can promote this culture through some novel activities to increase brand awareness. For example, cultural tourism festivals and regular competitions on brand cultural knowledge are held to strengthen the cultural identity of employees and consumers.

The innovation of the system is conducive to improving the overall vitality and management efficiency of the company. Xie Shouxiang (2017) believed that institutional innovation must be combined with actual practice of the company [15]. For example, intangible cultural heritage enterprises with local and cultural characteristics, in consideration of the inheritance system, it may be considered to "separate production without business". This institutional innovation mainly reflects the separation of ownership and management rights, and promotes the stability and continuation of the enterprise distribution mechanism. Companies should learn to combine their own innovation in a timely manner.

Talents are the inexhaustible motive force for enterprise technology research 
and development. The introduction of innovative talents helps companies maintain strong competitive advantages. For example, innovative technology talents, in the context of internet big data, traditional enterprises also need to introduce talents of high technology. Zhao Shuming (2012) has studied the cultivation of innovative core scientific and technological talents and gave suggestions: Focus on the cultivation and development of local innovative core scientific and technological talents, and transform the development strategy for purely importing talents [16]. This is worth learning from non-material cultural heritage companies.

\subsection{Strengthen Mutually Beneficial Cooperation with Related Social Organizations}

\subsubsection{Strengthen Partnership with Government and Financial Institutions}

The government is the drafter of plans for the protection of intangible cultural heritage and is a strong backing for the development of non-inherited enterprises. Intangible enterprises must actively cooperate with the government. For example, actively participate in the education and training activities of the intangible cultural heritage inheritors held by government departments, and respond to various policies of the government. Appropriate capital flow is an important guarantee for the survival and development of non-inherited enterprises. Financial institutions are also indispensable supporters in the business process. Using the National Development and Reform Commission for the cooperation of cultural enterprises and financial institutions issued "Cultural Industry Special Bonds" is a good case in point. Making use of the IP pledge financing of intangible cultural heritage, it will keep its own brand image while reducing the cost of financing and win the trust of financial institutions.

\subsubsection{Good at Collaborating with Organizations Such as Universities and Media}

Being good at interacting with the news media also has a direct and indirect influence on the brand value. When enterprises organize events outside the country, they must make proper use of media resources and strengthen cooperation with media companies. For example, when a company sponsors certain program activities, it should grasp the media, television, advertising, and other media propaganda, and strengthen mutually beneficial cooperation such as tourism and museums. Useful information such as brand features and product effectiveness is widely communicated to consumers, deepening their brand image. Strengthen cooperation with universities in personnel training and technical exchanges. For example, companies hold creative exchange activities such as the "Innovative Design Competition for College Students on Intangible Cultural Heritage" in colleges and universities, regularly send enterprise personnel to attend university training courses, and cooperate with experts such as Chinese medicine to form long-term partnerships. 


\section{Summary}

In short, intangible cultural heritage enterprises are the carriers to protect and inherit Chinese traditional culture. Their future has a tremendous impact on the fate of Chinese cultural treasures. Therefore, in order to better develop the future of non-legacy enterprises, the state and the masses of the society must contribute to the promotion of traditional culture. The enterprises themselves must also improve their innovative capabilities and lay the foundation for the long-term development of the company.

\section{References}

[1] Yu, S.G. (2017) State Council Report on Cultural Heritage Work. China National People's Congress. http://www.npc.gov.cn/npc/xinwen/2017-12/23/content_2034497.htm?winzoom=1

[2] Finance and Economics (2017) No. 57. Notice of the Ministry of Finance on Issuing Special Fund for Intangible Cultural Heritage Protection in 2017. Ministry of Finance of the People's Republic of China. http://whs.mof.gov.cn/zxzyzf/fwz/201707/t20170704_2638113.html

[3] Xiao, X. (2007) Analysis of Brand Value Evaluation Method and Its Value Influencing Factors. Research Center of Accounting Development of Xiamen University, Institute of Financial Management and Accounting of Xiamen University, Department of Accounting of Xiamen University. Valuation: Frontiers and ChallengesThe 7th International Symposium on Accounting and Financial Issues, 10.

[4] Xiang, Y.S. (2009) Brand Competitiveness and Analysis Model. Commercial Research, 9, 179-181.

[5] Tian, J. and Zhai, Z.F. (2015) Research on the Promotion of Brand Value of High-Tech Innovative Enterprises-A Case Study of Huawei's Success in the Global Top 100 Brands. Scientific Management Research, 33, 82-85.

[6] Yuan, Z.M. and Ma, Y. (2008) Comparative Research on Chinese and Foreign Brand Evaluation. Modern Finance and Economics. Journal of Tianjin University of Finance and Economics, 3, 73-78.

[7] Shen, Y.Q. (2016) On Enterprise Management Expense Control. Money China, 5, 135-207.

[8] Li, J. and Meng, R. (2015) Problems in Enterprise Management Cost Management and Analysis of Countermeasure. Business, 8, 183.

[9] Zhou, C.L. (2014) The Value Evaluation of Brand Assets and the Consideration of Accounting Management. Appraisal Journal of China, 11, 31-34.

[10] Liu, C.Y. (2018) Business Closed Loop for Profits of Enterprises. Enterprise Management, 1, 38-40.

[11] China Business News (2013) Tong Ren Tang's Pesticide Residues Have Been Repeatedly Exposed. http://finance.sina.com.cn/consume/puguangtai/20130907/012016691990.shtml

[12] Chen, L. and Mei, L.Y. (2010) Discussion on the Obstacles and Countermeasures of Pledge and Evaluation of Intangible Assets. Finance and Accounting Monthly, 6, 37-39.

[13] Meng, F.S. and Zhang, G.C. (2011) Research on Double Dynamic Cost Control Mechanism. Accounting Research, 11, 78-82.

[14] Wei, S.H. and Zhou, B. (2015) Research on the International Competitiveness of 
China's High-tech Industry-Based on the Perspective of Technological Progress and Scale Economic Integration. Journal of Nanjing University (Philosophy. Humanities. Social Sciences), 52, 15-26.

[15] Xie, S.X. and Li, J. (2017) How to Continue the Glory of the Family Business Through the Intergenerational Inheritance-Reflections on the Innovation of the Inheritance System. Modernization of Management, 5, 47-49.

[16] Zhao, S.M., Li, Q.W. and Zhang, Y.F. (2012) Research on the Cultivation of Innovative Core Science and Technology Personnel and Policy Environment-An Empirical Analysis Based on 625 Questionnaires of Jiangsu Province. Journal of Nanjing University (Philosophy. Humanities. Social Sciences), 49, 49-57, 158-159. 